\title{
Epidemiological Study of the Lesions of the Brazilian Karate
}

\section{Paula C D Machado* and Hélio Plapler}

Department of Surgery - Paulista School of Medicine - UNIFESP, Discipline of Experimental Surgical Surgery Technique, Brazil

*Corresponding Author: Paula C D Machado, Department of Surgery - Paulista School of Medicine - UNIFESP, Discipline of Experimental

Surgical Surgery Technique, Brazil.

Received: May 14, 2019; Published: June 07, 2019

DOI: 10.31080 /ASOR.2019.02.0062

\begin{abstract}
Introduction: Karate is one of the most practiced fighting modalities in the world, but few works have been done in this area, especially in the Brazilian karate. In the international literature, this modality presents mild lesions, but severe lesions also occur frequently. In the Brazilian literature there is no specific epidemiological survey of the lesions in karate, making it difficult to analyze the risks of this sport.

Objective: to perform a retrospective epidemiological survey of acute traumatic injuries in karate modality.

Materials and Methods: Analysis of the athletes ' data through the recording of injuries collected by the first aid team that acted in the events.
\end{abstract}

Results: The five events counted with 3116 athletes and a total of 470 lesions were recorded.

Conclusion: We can affirm that karate is a sport that presents low incidence of injuries and, when they occur, are mostly mild lesions.

Keywords: Judo; Injuries; Epidemiology; Martial Arts; Trauma

\section{Introduction}

Karate is one of the most popular martial arts in the world and the number of practitioners has grown intensely in the last 10 years, both in male and female categories [1,2]. In England alone there are 12,000 karate fighters and in the USA they reach 1.5 - 2 million of practitioners [1,2]. In Brazil there are about 10000 karate fighters and almost 2500 are in the state of São Paulo [2]. It is estimated that $20 \%$ of these practitioners from all over the world are children and adolescents [1]

In karate the training consists of 3 basic classifications: "Kihon" consisting of basic techniques performed without opponent, the "Kata" which are combinations of techniques without opponent and the "Kumite" which is the simulation of the fight with a companion and the fight properly said. The competitions are differentiated by the styles chosen, and there are 5 different styles of karate and only one of them is considered Olympic, namely: Light contact or semi-contact (light or touch/semi contact) [3]. In this style the occurrence of serious injuries is not frequent. Most of them are made up of bruises, epistaxis and lacerations/abrasions, considered mild and affecting mainly the face and trunk $[2,4,5]$.
These injuries can cause abandonment during and after the competition, as there are certain rules that distance the sportsman from the event. Persistent bleeding, dental contusion, eye trauma, loss of consciousness, among others can be cited. The moderate and severe injuries that require the athlete to be removed from the competition may also be considered, temporarily from training and even from sports life $[2,4,5]$.

Therefore, the knowledge about the index, intensity and frequency with which these injuries occur during the championships may help in the prevention and proper treatment of these injuries during the tournaments and in the sports preparation of the athletes. This may be an extremely important instrument for the training team.

In the Brazilian literature, there is no record of the index of acute lesions during the Brazilian Karate Championships. In this way we propose a survey of the incidence and frequency of acute traumatic injuries recorded by the Rescuer Committee during the finals of the main championships held by the Paulista Federation of Karate (FPK) and the Brazilian Confederation of karate (CBK) to perform an epidemiological analysis of these lesions. This survey 
will create an epidemiological record of acute traumatic injuries in karate fights through the data collected by the rescuer committee of the events studied.

The objective of this study was to perform a retrospective epidemiological survey of the acute traumatic injuries in the karate modality.

\section{Materials and Methods}

The study was approved by the Research Ethics Committee of the Paulista School of Medicine under Number 1553/09. Data were recorded from the Attendance Committee of seven Championships of the Paulista Federation of Karate (FPK) and the Brazilian Karate Confederation (CBK). The collected data generated the "incident report" from the Medical department's board of Directors. Those who attended the championships had prior medical release and were considered fit to fight.

We analyzed the records of injuries of athletes of both sexes, aged between 5 and 48 years, of various weights, in the amateur, experienced and high-level categories. According to the rules of FPK/CBK and the event, all participants should present at least one year of training at the different undergraduate levels. The study participants were those who suffered some kind of traumatic injury during the fight or sought care in the interval periods and were attended by the team of first aid of the event. Also included were those who needed removal to the hospital unit.

During The championships, only those athletes who presented injury during the fight and all the athletes who sought care in the period between fights with complaints of previous injuries and post-fight were attended.

To define the different levels of data analysis, the results were defined as:

Age record or dispute category (CD): All championships are defined by the age of athletes according to sport rules. In this study we only distribute the participants by age, they are: adults older than 17 years and juvenile younger than 17 years. In this we exclude the Open Championship by tracks;

The classification of the types of lesions provided by Arriza [11] and Fetto [12] was used and the definition of the severity degree of the lesion followed the classification of Fetto [12] and Simões [13] (Table 1). The lesion site initially followed the study of Barsottini ${ }^{4}$ and Halabchi [14], and subsequently modified to adapt to subsites (Table 1).

\begin{tabular}{|c|c|}
\hline Classification of injury Types $[11,13]$. & $\begin{array}{l}\text { Classification of the } \\
\text { degree of injuries } \\
{[11,12] .}\end{array}$ \\
\hline $\begin{array}{l}\text { Grade III concussion; Grade III Sprat; } \\
\text { Open fracture; Ocular injury; Visceral } \\
\text { lesions; Hemorrhages and dislocation } \\
\text { requiring reduction }\end{array}$ & Serious \\
\hline $\begin{array}{l}\text { Grade II concussion; Ocular contu- } \\
\text { sion; Crisis Grade II Sprat; Closed } \\
\text { fracture; Grade II laceration, epistaxis } \\
\text { and Dental injury }\end{array}$ & Moderate \\
\hline $\begin{array}{l}\text { Abrasion Fingernail avulsion; Bubble } \\
\text { Callus Cramp Contusion Distension } \\
\text { Grade I laceration; Tendinitis and } \\
\text { Subluxation }\end{array}$ & Slight \\
\hline $\begin{array}{l}\text { Lesion site According to the authors } \\
\text { who studied }[4,14] \text {. }\end{array}$ & Sublocal $[4,14]$ \\
\hline Region & Right and left \\
\hline Head, Face and neck (CFP) & $\begin{array}{l}\text { Face, nose, eyes, lip, } \\
\text { skull, Cervical region }\end{array}$ \\
\hline Trunk and Genitalia (TG) & $\begin{array}{l}\text { Abdomen, thorax, } \\
\text { coasts, genitalia, groin }\end{array}$ \\
\hline Upper Limbs (MMSS) & $\begin{array}{l}\text { Shoulder, arm, elbow, } \\
\text { forearm, wrist, hand, } \\
\text { hand fingers }\end{array}$ \\
\hline Lower Limbs (MMII) & $\begin{array}{l}\text { Hip, thigh, knee, leg, } \\
\text { ankle, foot, toes }\end{array}$ \\
\hline
\end{tabular}

Table 1: Classification of the types of lesions according to Fetto [11] and Arriza [13] and the degree of injury according to Fetto [11] and Simões [12] and lesion site according to Barsottini [4] and Halabchi [19].

Statistical analysis was performed using Fisher's exact test, with a significance limit of 0.05 or $5 \%$.

\section{Results}

3766 athletes participated in the nine championships. 475 visits were recorded.

\section{General}

The analysis of the results found in relation to the number of participants per championship, record of occurrence and distribution by age are described in table 2 .

475 occurrences were recorded. The general analysis of these consultations regarding age can be seen in table 3 . 


\begin{tabular}{|l|c|c|}
\hline & № participants. & № first aid care. \\
\hline Youth & 2946 & $353(12,0 \%)$ \\
\hline Adult & 820 & $122(14,9 \%)$ \\
\hline & & No first aid care. \\
\hline Youth & & 353 \\
\hline Adult & & 122 \\
\hline
\end{tabular}

Table 2: Relation of the general number of participants in relation to the recorded injuries.

\begin{tabular}{|l|c|c|c|}
\hline & General & Adult & Youth \\
\hline & $475(100 \%)$ & $122(25,7 \%)$ & $353(74,3 \%)$ \\
\hline Degree of injury & General & Adult & Youth \\
\hline Take & $89,3 \%(424)$ & $88,5 \%(108)$ & $89,5 \%(316)$ \\
\hline Moderate & $7,6 \%(36)$ & $10,7 \%(13)$ & $6,5 \%(23)$ \\
\hline Serious & $3,2 \%(15)$ & $0,8 \%(1)$ & $4,0 \%(14)$ \\
\hline $\begin{array}{l}\text { * Fisher's exact test, } \\
\text { p-value difference. }\end{array}$ & & & \\
\hline
\end{tabular}

Table 3: Result of the general analysis of the consultations in relation to CD and answering tables.

The results found analyzing the types of lesions, degree of injury, specific region of the body and side of the lesion in relation to age are described in table 4.
Relationship between lesion site versus injury type

The relationship between lesion site versus type of injury can be seen in table 5 .

\begin{tabular}{|l|c|c|c|c|}
\hline \multicolumn{1}{|c|}{ Type of injury } & General & Adult & Youth & P-Value \\
\hline Bruise & $61,1 \%(291)$ & $38,2 \%(47)$ & $69,1 \%(244)$ & $* \mathrm{P}<0.001$ \\
\hline Laceration & $13,0 \%(62)$ & $24,4 \%(30)$ & $9,1 \%(32)$ & $* \mathrm{P}<0.001$ \\
\hline Epistaxis & $8,0 \%(38)$ & $16,3 \%(20)$ & $5,1 \%(18)$ & $* \mathrm{P}<0.001$ \\
\hline Abrasion & $4,2 \%(20)$ & $8,1 \%(10)$ & $2,8 \%(10)$ & $* \mathrm{P}=0,018$ \\
\hline Concussion & $5,7 \%(27)$ & $8,1 \%(10)$ & $4,8 \%(17)$ & 0,178 \\
\hline Sprain & $2,1 \%(10)$ & $1,6 \%(2)$ & $2,3 \%(8)$ & 1,000 \\
\hline Dislocation & $1,9 \%(9)$ & $0,8 \%(1)$ & $2,3 \%(8)$ & 0,458 \\
\hline Bleeding Bubble & $1,7 \%(8)$ & $0,8 \%(1)$ & $2,0 \%(7)$ & 0,686 \\
\hline Fainting & $0,8 \%(4)$ & $0,8 \%(1)$ & $0,8 \%(3)$ & 1,000 \\
\hline Nail avulsion & $0,4 \%(2)$ & $0,0 \%(0)$ & $0,6 \%(2)$ & 1,000 \\
\hline Cramp & $0,2 \%(1)$ & $0,8 \%(1)$ & $0,0 \%(0)$ & 0,258 \\
\hline Fracture & $0,2 \%(1)$ & $0,0 \%(0)$ & $0,3 \%(1)$ & 1,000 \\
\hline Tendinitis & $0,4 \%(2)$ & $0,0 \%(0)$ & $0,6 \%(2)$ & 1,000 \\
\hline Distention & $0,0 \%(0)$ & $0,0 \%(0)$ & $0,0 \%(0)$ & \\
\hline Subluxation & $0,0 \%(0)$ & $0,0 \%(0)$ & $0,0 \%(0)$ & \\
\hline Injury site & General & Adult & Youth & P-Value \\
\hline CFP & $46,6 \%(220)$ & $66,7 \%(82)$ & $39,5 \%(138)$ & $* \mathrm{P}<0.001$ \\
\hline
\end{tabular}




\begin{tabular}{|c|c|c|c|c|}
\hline $\mathrm{TG}$ & $16,9 \%(80)$ & $6,5 \%(8)$ & $20,6 \%(72)$ & $* \mathrm{P}<0.001$ \\
\hline MMSS & $14,0 \%(66)$ & $7,3 \%(9)$ & $16,3 \%(57)$ & ${ }^{*} \mathrm{P}=0,015$ \\
\hline MMII & $22,5 \%(106)$ & $19,5 \%(24)$ & $23,5 \%(82)$ & 0,238 \\
\hline CFP & General & Adult & Youth & P-Value \\
\hline Face & $16,4 \%(36)$ & $16,0 \%(13)$ & $16,7 \%(23)$ & 1,000 \\
\hline Nose & $22,4 \%(49)$ & $28,4 \%(23)$ & $18,8 \%(26)$ & 0,130 \\
\hline Eyes & $2,7 \%(6)$ & $2,5 \%(2)$ & $2,9 \%(4)$ & 1,000 \\
\hline Lip & $25,6 \%(56)$ & $32,1 \%(26)$ & $21,7 \%(30)$ & 0,109 \\
\hline Skull & $21,9 \%(48)$ & $17,3 \%(14)$ & $24,6 \%(34)$ & 0,238 \\
\hline Cervical Region & $11,0 \%(24)$ & $3,7 \%(3)$ & $15,2 \%(21)$ & ${ }^{*} \mathrm{p}=0,007$ \\
\hline TG & General & Adult & Youth & P-Value \\
\hline Abdomen & $30,9 \%(25)$ & $33,3 \%(3)$ & $30,6 \%(22)$ & 1,000 \\
\hline Chest & $51,9 \%(42)$ & $55,6 \%(5)$ & $51,4 \%(37)$ & 1,000 \\
\hline Coasts & $1,2 \%(1)$ & $0,0 \%(0)$ & $1,4 \%(1)$ & 1,000 \\
\hline Genitalia & $12,3 \%(10)$ & $11,1 \%(1)$ & $12,5 \%(9)$ & 1,000 \\
\hline Groin & $3,7 \%(3)$ & $0,0 \%(0)$ & $4,2 \%(3)$ & 1,000 \\
\hline MMSS & General & Adult & Youth & P-Value \\
\hline Shoulder & $3,0 \%(2)$ & $11,1 \%(1)$ & $1,8 \%(1)$ & 0,256 \\
\hline Arm & $9,1 \%(6)$ & $0,0 \%(0)$ & $10,5 \%(6)$ & 0,585 \\
\hline Elbow & $15,2 \%(10)$ & $22,2 \%(2)$ & $14,0 \%(8)$ & 0,616 \\
\hline Forearm & $12,1 \%(8)$ & $11,1 \%(1)$ & $12,3 \%(7)$ & 1,000 \\
\hline Handle & $4,5 \%(3)$ & $0,0 \%(0)$ & $5,3 \%(3)$ & 1,000 \\
\hline Hand & $4,5 \%(3)$ & $0,0 \%(0)$ & $5,3 \%(3)$ & 1,000 \\
\hline Hand Fingers & $51,5 \%(34)$ & $55,6 \%(5)$ & $50,9 \%(29)$ & 1,000 \\
\hline MMII & General & Adult & Youth & P-Value \\
\hline Hip & $1,9 \%(2)$ & $0,0 \%(0)$ & $2,4 \%(2)$ & 1,000 \\
\hline Thigh & $10,4 \%(11)$ & $12,5 \%(3)$ & $9,8 \%(8)$ & 0,709 \\
\hline Knee & $13,2 \%(14)$ & $20,8 \%(5)$ & $11,0 \%(9)$ & 0,301 \\
\hline Leg & $27,4 \%(29)$ & $37,5 \%(9)$ & $24,4 \%(20)$ & 0,297 \\
\hline Ankle & $8,5 \%(9)$ & $0,0 \%(0)$ & $11,0 \%(9)$ & 0,204 \\
\hline Foot & $17,9 \%(19)$ & $12,5 \%(3)$ & $19,5 \%(16)$ & 0,554 \\
\hline Toes & $20,8 \%(22)$ & $16,7 \%(4)$ & $22,0 \%(18)$ & 0,776 \\
\hline Body side & General & Adult & Youth & P-Value \\
\hline Right & $55,8 \%(101)$ & $54,3 \%(19)$ & $56,2 \%(82)$ & 0,852 \\
\hline Left & $44,2 \%(80)$ & $45,7 \%(16)$ & $43,8 \%(64)$ & 0,852 \\
\hline $\begin{array}{l}\text { * Fisher's exact test, } \\
\text { p-value difference. }\end{array}$ & & & & \\
\hline
\end{tabular}

Table 4: The result of the analysis of the type of injury in relation to age. 


\begin{tabular}{|c|c|c|c|}
\hline Injury & Local & $\%(n+o)$ & \multirow{27}{*}{$\begin{array}{l}\text { General analysis } \\
\text { Outed in the tournaments, representing } 12.5 \% \text { of the total number } \\
\text { of participants. Each care corresponded to at least one injury. } \\
\text { Regarding the number of participants, the adult category } \\
\text { presented a higher proportion of visits. Perhaps this result is the } \\
\text { reflection of a mathematical logic, because the adult has fewer } \\
\text { athletes participating in this modality in relation to juvenile } \\
\text { and thus a small record of injuries will be statistically higher in } \\
\text { a smaller population, as shown in table } 2 \text {. This may also occur } \\
\text { because the adult has greater experience in the combat and, when } \\
\text { attempting to protect himself from serious injuries, interrupts the } \\
\text { fight constantly for any reason, opposite of juvenile that loses the } \\
\text { notion of protection, risk and strength. Franchine., et al. [11] report } \\
\text { that young athletes have a more aggressive behavior characteristic } \\
\text { of age, less experience and less technical knowledge in combat, } \\
\text { exposing themselves more during the combat, but at the same time, } \\
\text { resist pain and request less during the fight (table 2). Although } \\
\text { these observations come from judo, it is lawful to imagine that they } \\
\text { are valid for any kind of martial art. Moreover, it knows-sand that } \\
\text { athletes of the adult/senior category have a lower metabolic and } \\
\text { muscular capacity, causing them not to support the demands of } \\
\text { the sport, provoking a higher frequency of injuries in this category } \\
\text { [4,5,7,11]. We did not find any studies that report these findings for } \\
\text { a better comparison. This characteristic is repeated in the various } \\
\text { analyses of the lesions (grade, type, age, location) as we will see } \\
\text { below. }\end{array}$} \\
\hline \multicolumn{3}{|l|}{ Bruise } & \\
\hline & Chest & $13,7 \%(40)$ & \\
\hline & Face & $9,2 \%(27)$ & \\
\hline & Cervical region & $8,2 \%(24)$ & \\
\hline & Abdomen & $8,2 \%(24)$ & \\
\hline & Hand Fingers & $8,2 \%(24)$ & \\
\hline & Leg & $7,9 \%(23)$ & \\
\hline & Skull & $7,2 \%(21)$ & \\
\hline & Knee & $4,1 \%(12)$ & \\
\hline & Toes & $4,1 \%(12)$ & \\
\hline & Thigh & $3,8 \%(11)$ & \\
\hline & Foot & $3,8 \%(11)$ & \\
\hline & Nose & $3,4 \%(10)$ & \\
\hline & Genitalia & $3,4 \%(10)$ & \\
\hline & Other (B) & $14,7 \%(43)$ & \\
\hline Abrasion & & & \\
\hline & Lip & $20,0 \%(4)$ & \\
\hline & Foot & $20,0 \%(4)$ & \\
\hline & Face & $15,0 \%(3)$ & \\
\hline & Leg & $15,0 \%(3)$ & \\
\hline & Chest & $10,0 \%(2)$ & \\
\hline & Other (A) & $20,0 \%(4)$ & \\
\hline Bleeding Bubble & & & \\
\hline & Foot & $37,5 \%$ (3) & \\
\hline & Toes & $37,5 \%(3)$ & \\
\hline & Leg & $25,0 \%(2)$ & \\
\hline
\end{tabular}

Analyzing only 475 occurrences, the highest percentage of injuries affected the juvenile group, being triple in relation to the adult (table 3). Similarly as described above, these findings may be imputed to age $[4,5,7,11]$. We also verified, looking at the degree of injury, that these were mostly mild lesions without differences between the categories counterpoint some authors [14,15]. We'll see more details below.

\section{Lesion analysis}

\section{Degree and type of injury}

Our results showed that mild lesions were the most frequent, with almost $90 \%$ of the occurrences. These findings can be justified by the biomechanics of the sport, since this modality (semi contact) should promote the smallest possible contact, only the one who offered the score in the [2,3] fight. Been such to the types of injuries, we found that the contusion, laceration and epistaxis were the most frequent, corroborating Critchley., et al. [12], because it was expected that, in a semi-contact sport, during the fight more vigorous accidental contacts occur among athletes provoking these types of injuries. Thus, these findings affirm that because it is a semi-contact modality the lesions that occur in this sport, are largely due to accidental contacts during the combat. Comparison with other studies was not possible.

Moderate lesions were the second most frequent record for the degree of injury. Injuries such as concussion and sprat are less frequent, but more intense. They are, in general, due to very close blows, counterblow, imbalances during the shifts in the fight, accidental impacts, errors in biomechanics, among others.

\begin{tabular}{|l|}
3 , shoulder 2 , cuff 2 , hip 2 , back 1 , hand 1 \\
\hline (C) Elbow 1 , cuff 1 , toes 1 \\
\hline (D) Toes 2 , cuff 1 , foot 1 \\
\hline
\end{tabular}

Table 5: Analysis of the relationship between lesion type versus site of injury. 
Our findings obtained with immediate care showed that severe lessons are rare in karate, not reaching 3.5\% of the total. Injuries such as hemorrhages, bleeding traumas, dislocation and fractures should be dealt with immediately by interrupting the struggle and sometimes requiring hospitalization. Literature [10], a methodologically closer study of ours, describes that this sport has a low frequency of serious injuries when compared to other sports. Critchley., et al. [12] they describe that the incidence of injuries per fight is less than 0.09 and 0.13 per competitor, showing that karate has a low incidence of injuries, agreeing with our findings [10]. Other studies report that karate has a frequency of lesions of 16$30 \%$, being these serious injuries $[14,15]$. These studies, however, were made with retrospective records of the injuries recorded by the medical departments, then only records of serious injuries and no injuries occurred during the competition, which determines the difference between the findings.

\section{Injury site}

Analyzing the results regarding the site of the lesion, we found consonance with the literature that states that the CFP region was the most affected $[12,15,16]$, understood as face the whole anterior region of the face except nose, eyes and lips. Of course, considering that any score in the sport is hitting the face, it was expected that this area would be the most affected [2,3]. Authors [10,12,15,16] describe that the use of protectors greatly decreased the rates of injuries in this region in the sport, but the lack of technique in kicks and punches performed inadequately during the fight (mainly with bony prominence) Still contribute to these results. In this region, we verified that the lip, nose and skull were the most frequently affected, confirming our previous theory that the search for scoring in the fight promotes the high frequency of injuries in this area $[10,12,15,16]$.

The second most frequently affected region was the lower limbs, with the leg, toes and foot being the three most frequently affected sites. This can be explained by the very biomechanics of the sport that requires many punches and kicks for the score gain. The kicks in particular, give higher scores in relation to the punches, then it was to be expected that these injuries were more frequent by the search for higher score $[10,12,15,16]$.

The third most frequently affected region was TG and within this region the thorax, abdomen and genitalia were the three most affected sites. Perhaps due to the fact that the simplest point is the $\mathrm{e}^{2.3}$ thorax area (abdomen and chest) and, when the athlete does not have much technique or experience, aim at the largest corporeal area of the body making it the simplest/easiest place to score. As for the region of genitalia, we believe, as some authors $[10,15,16]$, that are due to error of blows during the combat.

We did not find significant differences regarding the laterality of the lesion, although there was a higher occurrence of lesions on the right side. Considering that most of the population is right-handed, these findings were expected.

Age-related analysis (adult and juvenile)

Degree and type of injury

As previously mentioned, both categories presented a higher frequency of mild lesions, but we found some particularities regarding the type of injury $X$ category. Juvenile showed significant differences for the contusion, almost double in relation to the adult. This proves our previous findings and can be explained and confirmed by the injury itself, because the contusion is considered as a type of lesion intimately linked to the lack of technique and excessive aggressiveness, because the athlete who has no technique attacks in quantity and not quality, erring almost all your scams $[2,3,11]$. This is confirmed when we analyze the other results by type of injury, because the adult also presented differences for laceration, epistaxis and abrasion that are also considered mild injuries, but rather than juvenile, We believe that adults have a greater perception of effort associated with experience in the modality allowing to perform more precise blows and, as a consequence, triggering [11] sharp and bleeding injuries, which the rule of the sport requires immediate treatment $[2,3]$.

The adult presented a higher frequency of occurrences for the moderate lesions. Within this universe, the adult also presented a higher frequency of occurrences for the concussion, almost double in relation to juvenile. The concussion only occurs when a punch is well designed and executed by the athlete, thus necessitating a high precision. This only occurs more frequently with adults because they are more experienced and possess a better technical-tactical component, allowing a greater ease in the execution of precise blows, resulting in these findings. The juvenile presented a higher frequency of lesions for the sprat. The biomechanics of this sport is not characterized by having closed kinetic chains that increase the probability of sprains $[5,8,11,13]$, resulting from imbalances during shifts (jumps) during the fight and punches inadequate and inappropriate.

Juvenile showed a higher frequency of care for severe injuries. Within the moderate lesions, juvenile presented a higher frequency 
for luxation, almost triple in relation to the adult. Again, the biomechanics of sport is not characterized by closed kinetic chains, punches and inadequate movements are responsible for these findings $[5,8,11,13]$.

\section{Lesion site}

Regarding the lesion site, the adult presented differences for the CFP region, confirming our theory previously discussed in relation to the type of injury (concussion), where we believe that the adult aims to hit the highest score of the modality. We can affirm then that, the more experienced the athlete, the greater will be his technical-tactical capacity and his confidence in the combat generating greater accuracy by striking the head, providing a higher frequency of injuries, both mild and moderate, in the CFP Confirming the findings of the adult for the lesion sites: lip and nose. The juvenile presented higher frequency for the skull (higher score) and differences for the cervical region (almost triple) in relation to the adult. These findings corroborate Moura and Silva [15] who report that, in addition to the head and neck presenting the highest incidence found in their study, it was also the site with the highest probability of suffering injuries. As the head, with a kick, represents the region with the highest score, becomes the main target in the fight and, as the juvenile tends to be more aggressive with less technical-tactical capacity, end up hitting the cervical region [11].

Juvenile also showed differences, triple, for TG, with genitalia, groin and back the most frequently affected sites. Once again, these findings can be explained by the lack of technique and aggressiveness of young people, since the backs are worth the second highest point and, in general, are due to against [2,3] blows. The genitalia and the groin do not represent punctuation in the $[2,3]$ sport and are due to wrong blows or counterblow. On the other hand, the adult presented a higher frequency of care for the abdomen and thorax, showing once more a better accuracy of the blows, as previously explained.

The juvenile showed differences for the MMSS, twice as compared to the adult. Within the MMSS region, the adult presented a higher frequency of care for the shoulder, elbow and fingers of the hand. Perhaps these findings can be explained by the biomechanics of the sport added to the athlete's experience, since the greater the precision of the punch, the greater the impact force on the same due to the vibratory forces dissipated by the MMSS. Souza [17] reports that 3 factors are determinant for the increase of lesions in MMSS in Karate's: The increase of the athlete's age, substantial increase in training (mainly repetitions) and heavy training (overload). Biomechanically, the main factor for lesions in MMSS is the position of the elbow during the shock (blow-punch), because it will develop impact forces on the hand, the elbow and the shoulder [17], because when the fitting of the MMSS happens at the moment of the punch, greater will be the vibration forces over the entire region of the MMSS, thus explaining the findings in the adult. The juvenile, presented a higher frequency of attendance for all other sites, proving the technical inaccuracy of them.

Juvenile showed a higher frequency of care for the lower limbs, again being explained by aggressiveness and lack of technique. Within the region of the lower limbs, the adult presented a higher frequency of care for the leg, knee and thigh. Perhaps this can be explained by the decrease in metabolic capacities with age and thus, notwithstanding the requirements [11], it ends up overloading the thigh and leg. Juveniles presented a higher frequency of attendance for all other sites. Within the biomechanics of the sport the ankle, the foot and toes end up absorbing all the impacts of the attacks and the constant changes of direction/jumps during the $[2,3]$ fight. It is known that the smaller technical-tactical component of an athlete in a fighting modality that requires jumps and kicks, the greater the probability of the same to generate lesions in these places, thus justing the findings for the Juvenil $[3,5-8,12]$.

We did not verify differences between ages in relation to the side of the lesion. We only verified that the juvenile showed a higher frequency for the right side and the adult for the left side, perhaps because the adult has more experience and train blows to both sides, thus justing this increase to the left side.

\section{Lesion Analysis versus site of injury.}

This analysis revealed that the contusion most frequently affected the thorax and the face, and these findings were answered by the rules of the sport [2,3]. As in karate the point sites are: abdomen, chest and face (both minimum and maximum scores), every attempt at contact will be in this areas $[2,3]$.

Abrasion most frequently affected the lip and foot (in the same proportion) and the face and leg (in the same proportion). These findings can be justified by constant scoring attempts.

The bleeding bubble, as it was expected, committed the foot, toe and leg. This can be explained by the constant changes in direction and jumps performed during a combat and, as a consequence, end up triggering constant friction until the formation of bubbles. 
Already in the leg, the bubbles can be caused by constant kicks in the leg, both attack and defense, which ends up triggering bubbles.

The sprain most often affected the ankle and fingers of the hand. The ankle sprain can be justified by the constant changes of direction and jumps in the combat that, with the dynamics of it, ends up unbalancing the athlete who ends up suffering this type of injury. Already the sprat of the fingers of the hand is derived from the punches themselves in the fight.

The laceration, as it was expected, made the lip and face. As the highest score in the sport is to reach any region of the head and face, punches and kicks, biomechanically executed right or wrong, would cause these injuries.

The dislocation most frequently affected the fingers of the hand and, to a lesser frequency, the knee. We can affirm that inadequately executed punches would cause this high frequency of dislocation in the fingers and wrong displacements (jumps) would also cause the dislocation of the knees. In this sport, these injuries are intimately linked to the wrong biomechanics in the combat.

The concussion, as expected, affects only the skull and this is related to knockout. Also as expected, the epistaxis could only affect the nose and this related the attempt to hit the highest score in the sport.

Some of our findings were rare occurrences, such as the avulsion of fingernail, cramp, tendinitis and fracture. They may represent only casual incidences and are related to physical unpreparedness and/or previous fatigue of the athlete and by accidents during the fight $[11,14,15]$.

The great difference in this study was to present the immediate attendance data that occurred at the site of the fight in contrast to the retrospective work with the fact that it totally modifies the concept of the severity of the incidents in karate.

With the results of this study, the first aid teams will have a more accurate record of the most common immediate injuries of the sport, providing a logistic adequacy and a better screening of athletes during the event for a precise and fast attendance. Thus, we can provide the athlete with an efficient service with less risk of sequelae and, consequently, a lasting sporting life.

\section{Conclusion}

The record of injuries during the championships and during the fight itself revealed precisely which injuries the karate fighters are most likely to suffer and, mainly, how the team of first aid can prepare both technically and logistically to promote the faster and more efficient help, thus preventing sequelae resulting from delayed or poor pre-hospital care.

Within this universe, we can affirm that karate is a sport that presents a low incidence of injuries and, when they occur, are mostly mild lesions.

\section{Bibliography}

1. Ratti 0 and Westbrook A. "Secrets of the Samurai: The martial arts of Feudal Japan". Tóquio: Tutlle publishing (1991).

2. Paulista Karate Federation. Official report (2007).

3. Soares JGG. "Theory and practice of Karate-Dô Wado-Ryu. Editora Editora. Minas Gerais (1993).

4. Carazzato JG., et al. "Incidence of traumatic injuries in competitive athletes of ten types of sports modalities: individual work of two decades of specialist in sports medicine". Revista Brasileira de Ortopedia 27(1992): 745-758.

5. Parkkari J., et al. "Active living and injury risk". International Journal of Sports Medicine 25.3 (2004): 209-216.

6. Arriaza R and Leyes M. "Injury profile in competitive karate: prospective analysis of three consecutive World Karate Championships". Knee Surgery, Sports Traumatology, Arthroscopy 13.7 (2005): 603-607.

7. Fetto JF. "Judo and Karate-do. In: Sports Injuries: Mechanisms, prevention, treatment. Ed: Fu, F.H and Stone, D.A. Baltimore Williams and Wilkins. (1994) 455-468.

8. Simões NVN. "Sports injuries in practitioners of physical activity: a bibliographic review". Rev. Bras. Physiotherapy. 9.2 (2005): 123-128.

9. Barsotini D., et al. "Relationship between techniques and injuries in judo practitioners". Revista Brasileira de Medicina do Esporte 12.1 (2006): 56-60. 
10. Halabchi F., et al. "Injury profile in women Shotokan Karate Championships in Iran". Journal of Sports Science and Medicine. 6 (CSSI-2) (2007): 52-57.

11. Franchini E. "Judo: Competitive performance". São Paulo: Manole in (2001): 211-212.

12. Critchley GR., et al. "Injury rates in Shotokan karate". British Journal of Sports Medicine 33.3 (1999): 174-177.

13. Merrilee NZ., et al. "Injuries in martial arts: a comparison of five styles". British Journal of Sports Medicine 39.1 (2005): 2933.

14. Zataruk MN., et al. "Injuries in martial arts: a comparison of five styles". British Journal of Sports Medicine 39.1 (2005): 2933.

15. Moura AC., et al. "Musculoskeletal injuries in elite karate athletes: kata and kumite modality". Fisioterapia Brasil 12.5 (2011): 342-346.

16. Souza JMC., et al. "Lesions in Shotokan Karate and Jiu-Jitsu: Direct Trauma Versus Indirect". The Revista Brasileira de Medicina do Esporte 17.2 (2011): 107-110.

17. Souza VA. "Impact and risk analysis of upper segment injuries associated with the execution of the Gyaku Tsuy technique on Makiwara by karate practitioners of the Shotokan style. Master thesis-Federal University of Rio Grande do Sul. Porto Alegre (2002).

\section{Volume 2 Issue 7 July 2019}

(C) All rights are reserved by Paula C D Machado and

\section{Hélio Plapler.}

